\title{
Amelioration of the Cardiovascular Effects of Cocaine in Rhesus Monkeys by a Long-Acting Mutant Form of Cocaine Esterase
}

\author{
Gregory T Collins', Kathy A Carey', Diwahar Narasimhan', Joseph Nichols', Aaron A Berlin², \\ Nicholas W Lukacs', Roger K Sunahara', James H Woods' and Mei-Chuan Ko*, I \\ 'Department of Pharmacology, University of Michigan Medical School, Ann Arbor, MI, USA; ${ }^{2}$ Department of Pathology, University of Michigan \\ Medical School, Ann Arbor, MI, USA
}

\begin{abstract}
A long-acting mutant form of a naturally occurring bacterial cocaine esterase (TI72R/G I73Q CocE; double mutant CocE (DM CocE)) has previously been shown to antagonize the reinforcing, convulsant, and lethal effects of cocaine in rodents. However, the effectiveness and therapeutic characteristics of DM CocE in nonhuman primates, in a more clinically relevant context, are unknown. The current studies were aimed at ( 1 ) characterizing the cardiovascular effects of cocaine in freely moving rhesus monkeys, (2) evaluating the capacity of DM CocE to ameliorate these cocaine-induced cardiovascular effects when administered 10 min after cocaine, and (3) assessing the immunological responses of monkeys to DM CocE following repeated administration. Intravenous administration of cocaine produced dose-dependent increases in mean arterial pressure (MAP) and heart rate (HR) that persisted throughout the 2-h observation period following a dose of $3.2 \mathrm{mg} / \mathrm{kg}$ cocaine. Cocaine failed to produce reliable changes in electrocardiograph (ECG) parameters, body temperature, and locomotor activity. DM CocE produced a rapid and dose-dependent amelioration of the cardiovascular effects, with saline-like MAP measures restored within 5-10 min, and saline-like HR measures restored within 20-40 min of DM CocE administration. Although administration of DM CocE produced increases in anti-CocE antibodies, they did not appear to have a neutralizing effect on the capacity of DM CocE to reverse the cardiovascular effects of cocaine. In conclusion, these findings in monkeys provide strong evidence to suggest that highly efficient cocaine esterases, such as DM CocE, can provide a potential therapeutic option for treatment of acute cocaine intoxication in humans.
\end{abstract}

Neuropsychopharmacology (20 II) 36, I047-1059; doi:I0.1038/npp.20 10.242; published online 2 February 201 I

Keywords: rhesus monkey; cardiovascular; cocaine; acute cocaine toxicity; cocaine esterase; DM CocE

\section{INTRODUCTION}

Cocaine abuse remains a significant public health problem, with $\sim 2700$ people trying cocaine for the first time each day, and an estimated 2.1 million current cocaine users in the United States alone (SAMHSA, 2008). In addition, cocaine-related emergency department (ED) admissions continue to rise, and currently account for $\sim 57 \%$ of all illicit drug-related ED admissions, with over 550000 cases during the 2007 calendar year alone (SAMHSA, 2010). Although cocaine has a variety of physiological and psychological effects, including delirium, anxiety, panic, agitation, convulsion, and hyperthermia (Glauser and

*Correspondence: Dr M-C Ko, Department of Pharmacology, University of Michigan Medical School, I30I MSRB III, II50 West Medical Center Drive, Ann Arbor, MI 48109-0632, USA, Tel: + I 734 64731 19, Fax: + I 734764 7II8, E-mail: mko@umich.edu

Received 20 September 2010; revised 10 December 2010; accepted I I December 2010
Queen, 2007), the cocaine-associated chest pain, usually occurring within the first hour after cocaine use, is the most commonly reported reason for admission, accounting for $\sim 40 \%$ of all cocaine-related ED visits (Brody et al, 1990; Mittleman et al, 1999).

Although similar diagnostic strategies are used to evaluate cocaine-associated chest pain and other acute coronary syndromes, several of the standard therapeutics for acute coronary syndrome (eg, $\beta$-adrenergic antagonists and some antiarrythmics) are not only contraindicated, but may cause death (see, eg, Fareed et al, 2007) in patients under the influence of cocaine (McCord et al, 2008). Thus, intravenous (i.v.) benzodiazepines are typically used to alleviate chest pain and anxiety (McCord et al, 2008), but they do little to reverse cocaine-induced increases in mean arterial pressure (MAP), and heart rate (HR) (Baumann et al, 2000). Although the hypertensive and tachycardic effects of cocaine generally subside as the drug is metabolized (see, eg, Evans et al, 1996; Foltin and Fischman, 1991; Javaid et al, 
1978), cocaine has a variety of other direct effects including cardiac damage (eg, myocardial ischemia, left ventricular hypertrophy, and dilated cardiomyopathy; Hollander, 1995; Hollander and Henry, 2006). Thus, in addition to reducing cocaine-associated chest pain by eliminating the underlying cause for the increases in MAP and HR, therapeutics aimed at accelerating the metabolism of cocaine may have the added benefit of reversing the psychological effects of cocaine, while also reducing cardiac damage and the risk of future heart failure.

In humans, cocaine is primarily metabolized by serum butyrylcholinesterase (BChE), with a half-life (t1/2) of 45-60 min (Mendelson et al, 1999; Perez-Reyes et al, 1994) or longer depending upon the route of administration (Jeffcoat et al, 1989). To date, several different approaches to enhancing the metabolism of cocaine have been investigated including catalytic antibodies (Baird et al, 2000; Mets et al, 1998), mutated human BChEs (Brimijoin et al, 2008; Pan et al, 2005), and bacterial cocaine esterases (CocE; Larsen et al, 2002; Turner et al, 2002). Although human BChEs and bacterial CocE both metabolize cocaine to the inactive metabolites benzoic acid and ecgonine methyl ester, CocE does so with a catalytic efficiency (Kcat/ $\mathrm{Km}$ ) 800-fold greater than native BChE (Larsen et al, 2002; Turner et al, 2002), making it the most efficient natural cocaine-hydrolyzing enzyme identified to date. In rodent models of cocaine toxicity, wild-type (wt) CocE dose dependently protects against cocaine-induced cardiovascular changes, convulsion, and lethality (Cooper et al, 2006; Jutkiewicz et al, 2008; Ko et al, 2007; Wood et al, 2010). However, wt CocE is rapidly inactivated at body temperature, resulting in an in vivo $\mathrm{t} 1 / 2$ of $\sim 15 \mathrm{~min}$. Recent attempts to improve the thermostability of CocE through site-directed mutagenesis have identified an equally efficient mutant (T172R/G173Q) form of CocE (double mutant cocaine esterase (DM CocE)) with a significantly improved in vivo $\mathrm{t} 1 / 2$ ( $\sim 4.5 \mathrm{~h}$ in mice; Gao et al, 2008; Narasimhan et al, 2010). Indicative of its capacity to rapidly metabolize large amounts of cocaine in vivo, DM CocE has also been shown to dose dependently inhibit both the lethal and reinforcing effects of cocaine in rats (Collins et al, 2009).

Given that the majority of cocaine-related ED visits are because of the occurrence of cocaine-associated chest pain resulting from increases in MAP and HR, the goal of the current studies was to evaluate the capacity of DM CocE to ameliorate the cardiovascular effects of cocaine in rhesus monkeys. Although previous studies have described the effects of wt and DM CocE in rats and mice, these are the first studies to evaluate the effectiveness of CocE in a larger animal. Interestingly, despite the similarities between rhesus monkeys and humans with respect to their sensitivity to and metabolism of cocaine (Evans and Foltin, 2004; Mello et al, 2002; Mendelson et al, 1999), relatively little is known about how cocaine affects MAP and HR in rhesus monkeys (Carroll et al, 1990; Matsuzaki et al, 1976, 1978). Thus, the aims of the current studies were to: (1) characterize the cardiovascular (MAP, HR, and electrocardiograph (ECG) parameters) and physiological (body temperature and locomotor activity) effects of i.v. cocaine in freely moving rhesus monkeys, (2) evaluate the capacity of DM CocE to ameliorate the cardiovascular and physiological effects of cocaine, and (3) assess the development of immunological responses following administration of multiple doses of DM CocE.

\section{SUBJECTS AND METHODS}

\section{Subjects}

Two adult male and two adult female rhesus monkeys (Macaca mulatta) were used. Monkeys were singly housed in standard stainless steel monkey cages in an environmentally controlled room (temperature $21 \pm 3{ }^{\circ} \mathrm{C}$, relative humidity $30-70 \%$, and $10-15$ air changes per hour). Lighting was set for $12 \mathrm{~h}$ light, $12 \mathrm{~h}$ dark per $24 \mathrm{~h}$ with lights on at 0700 hours. The diet of the monkeys consisted of 20-50 Lab Fiber Plus Monkey Diet Chows (Lab Diet; PMI Nutrition International, LLC, Brentwood, MO), fresh fruit, and free access to water. Daily health checks were performed throughout the experiment to ensure that all monkeys remained healthy. All experimental procedures were approved by the University of Michigan Committee on the Use and Care of Animals and performed in accordance with the Guide for the Care and Use of Laboratory Animals, as adopted and promulgated by the National Institutes of Health.

\section{Surgical Preparation}

All monkeys were implanted with radio-telemetric probes (D70-PCT; DSI, St Paul, MN) to allow for the real-time collection of cardiovascular measures, core body temperature, and locomotor activity, as well as an indwelling venous catheter. Before surgery, monkeys were anesthetized with ketamine $(10 \mathrm{mg} / \mathrm{kg}$; intramuscular (i.m.)) and placed on a heating pad set to maintain the animal's body temperature at $\sim 37^{\circ} \mathrm{C}$. Monkeys were prepared by shaving the hair along the right flank, in the right inguinal area, just above the xiphoid process, and to the right of the right clavicle. All areas were scrubbed with alternating betadine/alcohol swabs. The telemetric probe was placed in a subcutaneous pocket on the right flank, and the attached blood pressure catheter was implanted in the femoral artery to allow for arterial pressure measures. ECG leads were passed subcutaneously to the areas above the xiphoid process and clavicle, and sutured to the muscle. All incisions were closed with 5-0 Ethilon suture, and monkeys were allowed 5-7 days to recover from surgery before implantation of an indwelling catheter in a jugular vein or the left femoral vein. For the second surgery, monkeys were similarly anesthetized and prepared. The vein was exposed and a silastic catheter was inserted and passed toward the heart. The distal end of the catheter was passed subcutaneously to an area between the shoulder blades and exited there. Monkeys were then fitted with mesh Teflon jackets (Lomir, Quebec, Canada) and attached to a flexible steel tether on a swivel to allow for relatively unrestrained movement in the home cage of the animals. Animals were allowed at least 7 days to recover before experimentation. Catheters were flushed daily with $3 \mathrm{ml}$ of saline to ensure catheter patency.

\section{Effects of Cocaine on MAP, ECG, Core Body Temperature, and Locomotor Activity}

The cardiovascular effects of i.v. cocaine were evaluated in each of the four rhesus monkeys, with each monkey 
receiving all five doses of cocaine $(0.0,0.1,0.32,1.0$, and $3.2 \mathrm{mg} / \mathrm{kg}$; i.v.) administered in random order and separated by at least 7 days to reduce the possibility for the development of tolerance to the cardiovascular effects of cocaine. Each dose of cocaine was followed by a $5 \mathrm{ml}$ saline flush to ensure the entire dose was delivered. Real-time measures of MAP, HR, QRS interval (QRSi), QT interval with Fridericia's correction (QTcf), ST elevation (STe), core body temperature, and locomotor activity were collected at $1 \mathrm{~s}$ intervals for at least $45 \mathrm{~min}$ before and $120 \mathrm{~min}$ after cocaine administration. Monkey M2 experienced a convulsion shortly $(\sim 30 \mathrm{~s})$ after receiving the $3.2 \mathrm{mg} / \mathrm{kg}$ dose of cocaine, which was reversed with an i.m. injection of $1.0 \mathrm{mg} /$ $\mathrm{kg}$ diazepam. The data for monkey M2 at the $3.2 \mathrm{mg} / \mathrm{kg}$ dose of cocaine are incomplete because of the removal of the receiver from the monkey's cage so that the monkey's condition could be monitored, and were therefore excluded from the statistical analyses.

\section{Effects of DM CocE on Cocaine-Induced Changes in MAP, HR, Core Body Temperature, and Locomotor Activity}

The capacity of DM CocE to alter cocaine-induced changes in MAP, HR, core body temperature, and locomotor activity was evaluated in each of the four rhesus monkeys. Doses of vehicle (phosphate-buffered saline (PBS)), 0.32, 1.0, or $3.2 \mathrm{mg} / \mathrm{kg}$ DM CocE were administered $10 \mathrm{~min}$ after the i.v. administration of $3.2 \mathrm{mg} / \mathrm{kg}$ cocaine in monkeys F1, F2, and $\mathrm{M} 1$, and after the i.v. administration of $1.0 \mathrm{mg} / \mathrm{kg}$ cocaine in monkey M2. A saline + PBS condition was also completed for each of the monkeys. No data were obtained from monkey M2 following administration of $1.0 \mathrm{mg} / \mathrm{kg} \mathrm{DM}$ CocE. This monkey experienced a convulsion following administration of $1.0 \mathrm{mg} / \mathrm{kg}$ cocaine during this phase of the study, and although $1.0 \mathrm{mg} / \mathrm{kg} \mathrm{DM}$ CocE was given to reverse the convulsion (successfully), the receiver was removed from the cage to allow for the monkey's condition to be monitored. In addition to the indicated doses of DM CocE, monkeys $\mathrm{F} 1$ and $\mathrm{M} 1$ also received smaller doses of the enzyme $(0.032$ and $0.1 \mathrm{mg} / \mathrm{kg}$; i.v.) $10 \mathrm{~min}$ after the administration of $3.2 \mathrm{mg} / \mathrm{kg}$ cocaine. The PBS control was always given before evaluation of DM CocE, and the doses of DM CocE used in each phase were administered in random order and separated by at least 7 days. Each dose of cocaine and DM CocE was followed by a $5 \mathrm{ml}$ saline flush to ensure that the entire dose was delivered, and real-time measures of MAP, HR, core body temperature, and locomotor activity were collected at 1-s intervals for at least $45 \mathrm{~min}$ before and $120 \mathrm{~min}$ after cocaine administration.

\section{Serum Collection}

In order to determine if monkeys were developing anti-DM CocE antibodies, serum samples were collected from each of the four monkeys throughout the DM CocE portion of the study. Beginning with the initial cocaine vs PBS condition, $2 \mathrm{ml}$ of blood was collected via the saphenous vein at 1-week intervals. During weeks in which monkeys were tested, serum samples were collected $24 \mathrm{~h}$ before the test session. Blood samples were collected without preservatives and stored on ice for $60 \mathrm{~min}$ before centrifugation at 4000 r.p.m. for $5 \mathrm{~min}$ at $4{ }^{\circ} \mathrm{C}$. Serum samples were pipetted into $2 \mathrm{ml}$ cryovials and stored at $-80{ }^{\circ} \mathrm{C}$ until being assayed for antiCocE antibody titer determinations.

\section{Immunological Determination}

A direct ELISA specific for anti-CocE antibodies was set up using a standard protocol. CocE was used $(1 \mu \mathrm{g} / \mathrm{ml})$ to coat a 96-well micro-titer plate using borate-buffered saline $(1.5 \mathrm{M}$ $\mathrm{NaCl}, 0.5 \mathrm{M} \mathrm{H} 3 \mathrm{BO} 3$, and $1.0 \mathrm{M} \mathrm{NaOH}$ ) to resuspend $\mathrm{CocE}$ $\left(50 \mu \mathrm{l} /\right.$ well). The coating plates were left overnight at $4{ }^{\circ} \mathrm{C}$. The coating buffer was removed the following morning and the plates blocked with $2 \%$ normal goat serum in PBS for $1 \mathrm{~h}$ at $37{ }^{\circ} \mathrm{C}$ and washed three times. Serum from the various monkeys was serially diluted in $50 \mu \mathrm{l}$ of PBS in the wells in a range of 102-107 and run in duplicate. The plates were covered and incubated for $1 \mathrm{~h}$ at $37^{\circ} \mathrm{C}$. Subsequently, the plates were washed three times and $50 \mu \mathrm{l} /$ well of goat antimouse IgG peroxidase-labeled antibody diluted 1:400 was added. The plates were then washed three times and $100 \mu \mathrm{l}$ peroxidase substrate solution (orthophenylenediamine (OPD) dissolved citrate/phosphate buffer) was added to each well. After 5-10 min of incubation (based upon color development in the positive controls), the reaction was stopped using $3 \mathrm{M} \mathrm{H} 2 \mathrm{SO} 4$ ( $50 \mu \mathrm{l} /$ well). The plates were read at $490 \mathrm{~nm}$ and titer was determined by the highest dilution that showed increases over background absorbance.

\section{Drugs}

Cocaine $\mathrm{HCl}$ was obtained from Mallinckrodt (St Louis, MO), and dissolved in $0.9 \%$ sterile saline to a concentration of $10.0 \mathrm{mg} / \mathrm{ml}$ and administered on a $\mathrm{mg} / \mathrm{kg}$ basis over $30 \mathrm{~s}$. DM CocE (T172R/G173Q CocE) was prepared, purified, and stored at $-80{ }^{\circ} \mathrm{C}$ until needed. Endotoxin levels from these preparations were assessed using an end point Limulus Amebocyte Lysate assay (Charles River) as per the manufacturer's specifications. These were $<30 \mathrm{EU} / \mathrm{ml}$, resulting in a maximal endotoxin $(\sim 2 \mathrm{ng} / \mathrm{ml}$ at the $3.2 \mathrm{mg} / \mathrm{kg}$ dose of DM CocE) below that what has been systematically evaluated in rhesus monkeys (Willette et al, 2007). Before administration, DM CocE $(5.0 \mathrm{mg} / \mathrm{ml})$ was thawed on ice and administered on a $\mathrm{mg} / \mathrm{kg}$ basis over a period of $10 \mathrm{~s}$.

\section{Data Analysis}

Baseline measures for MAP, HR, QRSi, QTcf, STe, and body temperature $\left({ }^{\circ} \mathrm{C}\right)$ represent the mean \pm SEM of the $15 \mathrm{~min}$ preceding each infusion, with the exception of locomotor activity, which represents the total locomotor activity observed during the 15-min period. Cardiovascular and physiological parameters were collected for $120 \mathrm{~min}$ after each infusion, and the effects of cocaine, or DM CocE, on each of the parameters were reported as the change from baseline for each 5-min block of time (mean of 5-min block-mean of $15 \mathrm{~min}$ before infusion). Mean change from baseline for each of the parameters represents the mean \pm SEM for either 60 or $120 \mathrm{~min}$ following cocaine infusions. The 60-min time frame was used to more clearly depict the dose dependency of the effects of DM CocE. Locomotor activity was summed over $5 \mathrm{~min}$ blocks, as well as over the entire $120 \mathrm{~min}$ period after cocaine administration. Two- 
way ANOVA with repeated measures and post hoc Bonferroni tests were used to determine if cocaine produced significant alterations in any of the cardiovascular or physiological parameters for each 5-min bin over the 120min period following cocaine infusion. One-way ANOVA with post hoc Newman-Keuls tests were used to determine if the cardiovascular or physiological parameters were significantly different from saline during the initial doseresponse determinations, or cocaine + PBS and saline + PBS during sessions in which DM CocE was administered after cocaine.

\section{RESULTS}

\section{Effects of Cocaine on MAP, ECG, Core Body Temperature, and Locomotor Activity}

The mean baseline measures for the $15 \mathrm{~min}$ preceding cocaine or saline infusion are shown in Table 1. Although each of the baseline parameters were within the expected range for rhesus monkeys, variability was observed both among monkeys and among experimental sessions for individual monkeys for each of the parameters with the exception of core body temperature.

\section{ECG Parameters}

Although cocaine had dose-dependent effects on QRSi in each of the four monkeys, these effects differed in onset, duration, magnitude, and direction across monkeys. In addition, large fluctuations in QRSi $(\sim 10-15 \mathrm{~ms})$, QTcf $(\sim 30 \mathrm{~ms})$, and STe $(\sim 0.1 \mathrm{mV})$ were observed at various times throughout the 120-min session with each of the four monkeys (data not shown), and there were no significant effects of cocaine on QRSi or STe when the data were grouped. Cocaine produced significant decreases in mean change in QTcf across the 120 -min session $(\mathrm{F}(4,14)=3.5$; $p<0.05$ ); however, significant changes in QTcf were only observed with a dose of $3.2 \mathrm{mg} / \mathrm{kg}$ cocaine (Figure 1). There were no effects of time from cocaine administration on the changes in QRSi, QTcf, or STe for the individual or grouped data.

\section{Body Temperature and Locomotor Activity}

Similar to the effects of cocaine on ECG parameters, cocaine produced changes in body temperature in each of the four monkeys (these effects differed across monkeys). Although cocaine decreased body temperatures in two monkeys (M1 and F1), increases in body temperatures were observed in the other two monkeys (M2 and F2). With respect to locomotor activity, cocaine produced dose-dependent decreases in three of the four monkeys (F1, F2, and M2); however, large, dose-dependent increases were observed in the fourth monkey (M1). As was observed with the ECG parameters, cocaine failed to significantly alter body temperature or locomotor activity when the data were grouped (Figure 1).

\section{MAP}

Reliable dose- and time-dependent increases in MAP were observed following i.v. cocaine administration in each of the four monkeys (dose: $\mathrm{M} 1: \mathrm{F}(4,92)=111.2 ; p<0.001 ; \mathrm{F} 1$ : $\mathrm{F}(4,92)=136.7 ; p<0.001 ; \mathrm{M} 2: \mathrm{F}(3,69)=71.2 ; p<0.001$; and $\mathrm{F} 2: \mathrm{F}(4,92)=54.4 ; \quad p<0.001$; time: $\mathrm{M} 1: \mathrm{F}(23,92)=4.9$; $p<0.001 ; \mathrm{F} 1: \mathrm{F}(23,92)=5.7 ; p<0.001 ; \mathrm{M} 2: \mathrm{F}(23,69)=3.9$; $p<0.001$; and $\mathrm{F} 2: \mathrm{F}(23,92)=2.6 ; p<0.001)$ as well as when the data were grouped (dose: $\mathrm{F}(4,322)=22.9 ; p<0.001$; time: $\mathrm{F}(23,322)=23.0 ; p<0.001)$. As shown in Figure 2 (left panels), rapid increases in MAP were observed following i.v. cocaine administration, with peak effects observed within the first $5 \mathrm{~min}$ of cocaine administration $(47.6 \pm 6.0 \mathrm{~mm} \mathrm{Hg}$ at $0.32 \mathrm{mg} / \mathrm{kg} ; 50.5 \pm 5.7 \mathrm{~mm} \mathrm{Hg}$ at $1.0 \mathrm{mg} / \mathrm{kg} ;$ and $68.2 \pm$ $8.7 \mathrm{~mm} \mathrm{Hg}$ at $3.2 \mathrm{mg} / \mathrm{kg}$ ). Although similar increases in MAP were observed with 0.32 and $1.0 \mathrm{mg} / \mathrm{kg}$ cocaine, the duration of the effect was dose dependent, with significant elevations in MAP observed for 15, 45, and 115 min following doses of $0.32,1.0$, and $3.2 \mathrm{mg} / \mathrm{kg}$ cocaine, respectively. Moreover, cocaine also produced a dose-dependent increase in the mean change in MAP over the entire 120-min observation period $(\mathrm{F}(4,14)=22.5 ; p<0.001)$, with doses of 1.0 and $3.2 \mathrm{mg} / \mathrm{kg}$ cocaine resulting in significant elevations in MAP when compared with saline.

\section{HR}

Similar to the effects of cocaine on MAP, dose-dependent increase in $\mathrm{HR}$ were observed in each of the four monkeys $(\mathrm{M} 1: \mathrm{F}(4,92)=92.2 ; p<0.001 ; \mathrm{F} 1: \mathrm{F}(4,92)=40.7 ; p<0.001$; M2: $\mathrm{F}(3,69)=178.6 ; \quad p<0.001 ;$ and $\mathrm{F} 2: \mathrm{F}(4,92]=43.8$; $p<0.001)$ as well as the grouped data $(\mathrm{F}(4,322)=6.7$; $p<0.01)$; however, there was no effect of time. As shown in

Table I Baseline Values for Cardiovascular Activity, Body Temperature, and Locomotor Activity in Rhesus Monkeys

\begin{tabular}{|c|c|c|c|c|c|}
\hline & $M I^{\mathbf{a}}$ & $\mathbf{F} \mathbf{I}^{\mathbf{a}}$ & $\mathbf{M} 2^{\mathbf{b}}$ & $\mathbf{F} \mathbf{2}^{\mathbf{a}}$ & Grouped \\
\hline Mean arterial pressure $(\mathrm{mm} \mathrm{Hg})$ & $106.7(2.9)$ & $107.9(1.9)$ & $96.6(2.0)$ & I03.3 ( 1.8$)$ & $104.0(1.2)$ \\
\hline Heart rate (b.p.m.) & I $27.7(4.6)$ & $140.9(2.3)$ & $99.0(3.5)$ & $139.2(2.6)$ & $128.2(2.7)$ \\
\hline QRS interval (ms) & $41.8(0.7)$ & $27.1(1.2)$ & $45.4(1.0)$ & $41.4(0.5)$ & $38.6(1.0)$ \\
\hline QT interval with Fredericia's correction (ms) & $307.3(2.5)$ & $310.0(3.3)$ & $319.9(2.8)$ & $302.2(1.3)$ & $309.3(1.5)$ \\
\hline ST elevation (mV) & $0.015(0.005)$ & $0.046(0.004)$ & $0.021(0.005)$ & $0.012(0.003)$ & $0.024(0.003)$ \\
\hline
\end{tabular}

a Values represent the mean \pm SEM for the I5-min periods before administration of saline or cocaine $(0.1,0.32,1.0$, and $3.2 \mathrm{mg} / \mathrm{kg}$; i.v.).

${ }^{b}$ Values represent the mean \pm SEM for the I5-min periods before administration of saline or cocaine $(0.1,0.32$, and I.0 mg/kg; i.V.). 

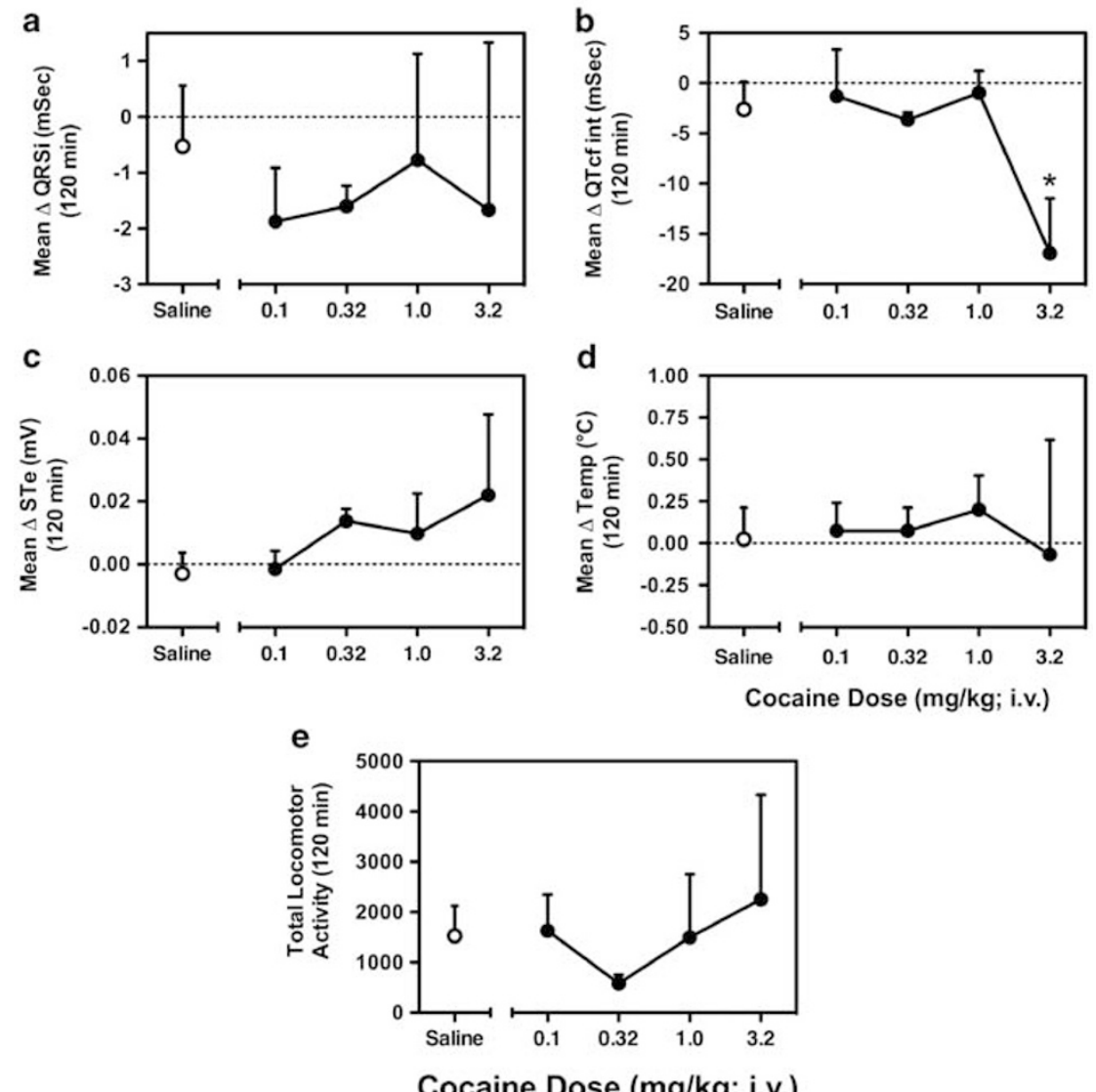

Figure I Dose-response curves for the effects of intravenous cocaine $(0.0,0.1,0.32,1.0$, and $3.2 \mathrm{mg} / \mathrm{kg})$ on ECG parameters, body temperature, and locomotor activity in rhesus monkeys. Data represent the mean \pm SEM $(n=4)$ change from baseline for (a) QRS interval, (b) QTcf interval, (c) ST elevation, (d) body temperature, or (e) the total locomotor activity over the $120 \mathrm{~min}$ observation period. Data points for the $3.2 \mathrm{mg} / \mathrm{kg}$ dose of cocaine represent the mean \pm SEM change from baseline for three monkeys. $* 2<0.05$. Significant difference from the saline condition as determined by one-way ANOVA with post hoc Newman-Keuls tests.

Figure 2 (right panels), when compared with the rapid onset of the MAP effects, the cocaine-induced increases in HR were slightly delayed, with peak increases in HR typically observed within the first 10-20 min after cocaine administration. In addition, unlike the increases in MAP that tended to subside gradually over the 120 -min session, the increases in HR were more persistent. However, transitory increases and/or decreases in HR of $\sim 15-35$ beats per min (b.p.m.) were occasionally observed in each of the four monkeys regardless of the dosing condition (data not shown). Nevertheless, when the data were grouped, cocaine produced a dose-dependent increase $(\mathrm{F}(4,14)=6.7 ; p<0.01)$ in the mean change in HR over the 120-min observation period, with a dose of $3.2 \mathrm{mg} / \mathrm{kg}$ cocaine resulting in mean change in HR measures that were significantly greater than saline $(p<0.01)$.

\section{Effects of DM CocE on Cocaine-Induced Increases in MAP}

The second phase of the study was performed identically to the initial dose-response determinations, with the exception that cocaine infusions $(3.2 \mathrm{mg} / \mathrm{kg}$ for $\mathrm{M} 1, \mathrm{~F} 1$, and $\mathrm{F} 2$, and $1.0 \mathrm{mg} / \mathrm{kg}$ for M2) were followed $10 \mathrm{~min}$ later by an i.v infusion of each of five doses $(0.032-3.2 \mathrm{mg} / \mathrm{kg})$ of DM CocE (M1 and F1), three doses $(0.32-3.2 \mathrm{mg} / \mathrm{kg}$ ) of DM CocE (F2), two doses $(0.32$ and $3.2 \mathrm{mg} / \mathrm{kg}$ ) of DM CocE (M2), or PBS (all monkeys). As shown in Table 2, reliable increases in MAP of a magnitude similar to those observed during the initial dose-response determination $(p=0.35)$ were observed $10 \mathrm{~min}$ after cocaine (ie, just before DM CocE) during each of these dosing conditions. When administered 10 min after cocaine, DM CocE produced a dose- and timedependent amelioration of the increases in MAP over the 120 -min period in each of the four monkeys (dose: F1: $\mathrm{F}(5,105)=55.4 ; p<0.001 ; \mathrm{F} 2: \mathrm{F}(3,63)=63.8 ; p<0.001 ; \mathrm{M} 1$ : $\mathrm{F}(5,105)=105.4 ; p<0.001 ; \mathrm{M} 2: \mathrm{F}(2,42]=48.9 ; p<0.001$; time: $\mathrm{F} 1: \mathrm{F}(21,105)=10.7 ; p<0.001 ; \mathrm{F} 2: \mathrm{F}(21,63)=24.8$; $p<0.001 ; \mathrm{M} 1: \mathrm{F}(21,105)=7.0 ; p<0.001 ; \mathrm{M} 2: \mathrm{F}(21,42)=2.8$; $p<0.01)$. The effects of DM CocE on MAP over the first $60 \mathrm{~min}$ are shown in Figure 3 (left panels) for a representative monkey (F1). Although doses of $0.1-3.2 \mathrm{mg} / \mathrm{kg} \mathrm{DM}$ CocE effectively returned MAP to baseline-like levels, this effect was generally observed sooner following administration of the larger doses (eg, $\sim 15 \mathrm{~min}$ with doses of 1.0 and $3.2 \mathrm{mg} / \mathrm{kg} \mathrm{DM}$ CocE, and $\sim 25 \mathrm{~min}$ with doses of 0.1 and $0.32 \mathrm{mg} / \mathrm{kg}$ in monkey F1). A similar dose dependency was observed with respect to the mean change in MAP over the first 60-min period, with a significant reduction in the mean change in MAP over the first 60-min period observed with lower dose of DM CocE, and saline-like MAP measures observed when $3.2 \mathrm{mg} / \mathrm{kg}$ cocaine was followed by either 1.0 or $3.2 \mathrm{mg} / \mathrm{kg}$ DM CocE. 

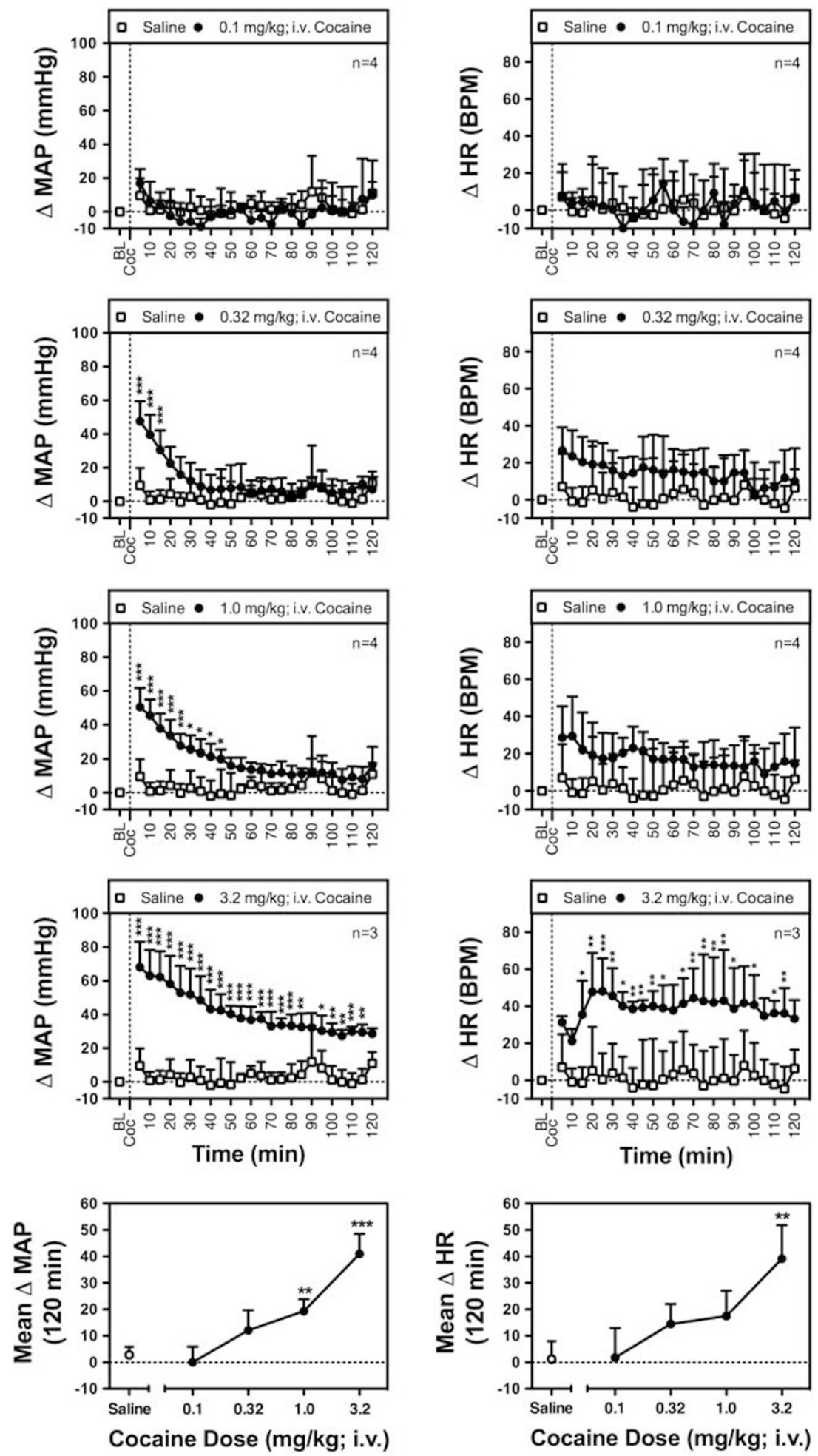

Figure 2 Effects of intravenous cocaine $(0.0,0.1,0.32,1.0$, and $3.2 \mathrm{mg} / \mathrm{kg}$ ) on mean arterial pressure (MAP; $\mathrm{mm}$ Hg), and heart rate (HR; b.p.m.) in rhesus monkeys. Data represent the grouped mean \pm SEM change from baseline for MAP (left panels) and HR (right panels) over successive 5-min blocks of time when compared with the MAP or HR effects of saline. The data for monkey M2 were excluded from the $3.2 \mathrm{mg} / \mathrm{kg}$ cocaine condition because of convulsion. $* p<0.05$; ** $p<0.01$; **** $p<0.00$ I. Significance points represent times at which MAP or HR measures were significantly greater than saline as determined by two-way ANOVA, repeated measures with post hoc Bonferroni tests. Dose-response curves for the effects of cocaine on MAP (bottom left panel) and HR (bottom right panel) represent the grouped mean \pm SEM change from baseline for MAP and HR over the I20-min period after cocaine administration. The effects of saline, $0.1,0.32$, and $1.0 \mathrm{mg} / \mathrm{kg}$ cocaine represent the mean \pm SEM change in MAP and HR for four monkeys, whereas the effects of $3.2 \mathrm{mg} / \mathrm{kg}$ cocaine represent the mean \pm SEM for three monkeys. $* * * 0.01$; **** $p<0.00$ I. Significant difference from the saline condition as determined by one-way ANOVA with post hoc Newman-Keuls tests. 
Table 2 Cocaine-Induced Changes in Mean Arterial Pressure and Heart Rate at the Time of DM CocE Administration

\begin{tabular}{|c|c|c|c|c|}
\hline Mean arterial pressure & MI & $\mathbf{F I}$ & M2 & $\mathbf{F 2}$ \\
\hline Baseline MAP $(\mathrm{mm} \mathrm{Hg})^{\mathrm{a}}$ & $95.4(2.2)$ & $94.4(1.7)$ & $86.4(8.1)$ & $96.7(0.9)$ \\
\hline Dosing condition & \multicolumn{4}{|c|}{ MAP $(\mathrm{mm} \mathrm{Hg})$ 10-min after cocaine ${ }^{b}$} \\
\hline PBS & 128.5 & 128.4 & 148.9 & 170.3 \\
\hline $0.032 \mathrm{mg} / \mathrm{kg}$ DM CocE & 140.6 & 126.3 & ND & ND \\
\hline $0.1 \mathrm{mg} / \mathrm{kg}$ DM CocE & 141.9 & 131.5 & ND & ND \\
\hline $0.32 \mathrm{mg} / \mathrm{kg}$ DM CocE & 127.9 & 125.6 & 140.0 & 160.3 \\
\hline 1.0 mg/kg DM CocE & 128.8 & | 32.1 & ND & 170.0 \\
\hline $3.2 \mathrm{mg} / \mathrm{kg}$ DM CocE & 128.4 & 125.7 & 160.8 & 161.0 \\
\hline Heart rate & MI & FI & M2 & $F 2$ \\
\hline
\end{tabular}

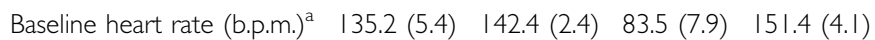

\begin{tabular}{lcccc}
\hline Dosing condition & \multicolumn{4}{c}{$H R$ (b.p.m.) 1 10-min after cocaine } \\
\hline PBS & 130.2 & 170.4 & 104.4 & 179.3 \\
$0.032 \mathrm{mg} / \mathrm{kg}$ DM CocE & 188.7 & 166.8 & $\mathrm{ND}$ & $\mathrm{ND}$ \\
$0.1 \mathrm{mg} / \mathrm{kg}$ DM CocE & 199.9 & 165.1 & $\mathrm{ND}$ & $\mathrm{ND}$ \\
$0.32 \mathrm{mg} / \mathrm{kg}$ DM CocE & 141.4 & 170.0 & 115.5 & 147.7 \\
$1.0 \mathrm{mg} / \mathrm{kg}$ DM CocE & 133.1 & 159.6 & $\mathrm{ND}$ & 183.8 \\
$3.2 \mathrm{mg} / \mathrm{kg}$ DM CocE & 169.9 & 168.3 & 116.1 & 180.3 \\
\hline
\end{tabular}

Abbreviation: ND, not determined.

${ }^{a}$ Values represent the mean \pm SEM MAP or HR for the 15 -min periods before i.v. administration of $3.2 \mathrm{mg} / \mathrm{kg}$ cocaine (MI, FI, and F2) or $1.0 \mathrm{mg} / \mathrm{kg}$ cocaine (M2) across dosing conditions.

bValues represent the MAP or HR for the I-min period immediately before the administration of PBS or DM CocE.

The effects of DM CocE on the cocaine-induced increases in MAP were also dose and time dependent when the data were grouped across the three monkeys that received the $3.2 \mathrm{mg} / \mathrm{kg}$ dose of cocaine (dose: $\mathrm{F}(5,220)=51.0 ; p<0.001$; time: $\mathrm{F}(21,220]=8.1 ; p<0.001)$. As shown in Figure 4 (left panels), MAP was elevated throughout the 120 -min session when administration of $3.2 \mathrm{mg} / \mathrm{kg}$ cocaine was followed by administration of PBS. However, these increases in MAP were significantly greater than saline only during the first $50 \mathrm{~min}$ after cocaine administration. When given $10 \mathrm{~min}$ after $3.2 \mathrm{mg} /$ $\mathrm{kg}$ cocaine, DM CocE $(0.32-3.2 \mathrm{mg} / \mathrm{kg})$ produced a rapid amelioration of cocaine's effects, resulting in MAP measures that were not statistically different from saline within 5$10 \mathrm{~min}$, and baseline-like MAP levels within the first 20$30 \mathrm{~min}$ following DM CocE administration. Once lowered, MAP remained at near baseline levels throughout the remainder of the 120-min observation period. DM CocE also produced a dose-dependent $(\mathrm{F}(5,10)=235.1 ; p<0.05)$ decrease in mean change in MAP over the entire 120-min session, with significant decreases in MAP observed following administration of doses of $0.32,1.0$, and $3.2 \mathrm{mg} / \mathrm{kg} \mathrm{DM} \mathrm{CocE}$ (Figure 4; bottom left panel). Although doses of 0.032 and $0.1 \mathrm{mg} / \mathrm{kg}$ DM CocE also decreased the elevations in MAP produced by $3.2 \mathrm{mg} / \mathrm{kg}$ cocaine, these data were excluded from statistical analyses because of the fact that only two monkeys completed these dosing conditions.

\section{Effects of DM CocE on Cocaine-Induced Increases in HR}

The HR-increasing effects of i.v. cocaine $(3.2 \mathrm{mg} / \mathrm{kg}$ for M1, $\mathrm{F} 1$, and $\mathrm{F} 2$, and $1.0 \mathrm{mg} / \mathrm{kg}$ for $\mathrm{M} 2$ ) were more variable than the effects of cocaine on MAP (Table 2). The mean change in HR during the cocaine + PBS condition was no different from that observed during the initial cocaine dose-response determination $(p=0.72)$. When administered $10 \mathrm{~min}$ after cocaine, DM CocE dose dependently altered the effects of cocaine on HR over the remainder of the session in each of the four monkeys (F1: $\mathrm{F}(5,105)=18.6 ; p<0.001 ; \mathrm{F} 2$ : $\mathrm{F}(3,63)=11.5 ; p<0.001 ; \mathrm{M} 1: \mathrm{F}(5,105)=49.7 ; p<0.001$; M2: $\mathrm{F}(2,42)=66.9 ; p<0.001)$. However, unlike the effects of DM CocE on MAP that clearly shortened the duration of cocaine's effects, time-dependent changes were only observed in monkey $\mathrm{F} 1(\mathrm{~F}(21,105)=4.2 ; p<0.001)$. Similar to the effects of DM CocE on MAP, HR measures generally returned to baseline-like levels following the administration of DM CocE at doses of $0.32-3.2 \mathrm{mg} / \mathrm{kg}$; however, this effect was generally observed sooner following administration of larger doses. For instance, doses of DM CocE ranging from 0.1 to $1.0 \mathrm{mg} / \mathrm{kg}$ returned $\mathrm{HR}$ to near baseline levels in monkey F1 within $40 \mathrm{~min}$, whereas a similar return to baseline measures of HR was observed $25 \mathrm{~min}$ after a dose of $3.2 \mathrm{mg} / \mathrm{kg}$ DM CocE (Figure 3; right panels). Despite the variability in the HR responses to cocaine across monkeys, DM CocE produced a significant dose-dependent amelioration $(\mathrm{F}(5,220)=18.7 ; p<0.001)$ of cocaine-induced increases in HR when the data were grouped (Figure 4; right panels). Similar to the effects of DM CocE on cocaineinduced changes in MAP, DM CocE decreased the mean change in HR over the 120-min session. Although treatment with DM CocE $(0.32-3.2 \mathrm{mg} / \mathrm{kg})$ resulted in saline-like HR responses for at least the last $60-80 \mathrm{~min}$ of the session in each of the four monkeys, there was no significant effect of DM CocE on the mean change in HR over the entire 120-min session when the data were grouped (Figure 4; bottom right panel).

\section{Effects of DM CocE on Cocaine-Induced Changes in Locomotor Activity and Core Body Temperature}

Similar to the effects observed during the initial doseresponse determination, an initial suppression of locomotor activity was observed in each of the monkeys when $3.2 \mathrm{mg} /$ $\mathrm{kg}$ cocaine was followed by administration of PBS. In two of these monkeys (M1 and F1), however, the initial suppression was followed by an increase in locomotor activity during the second $60 \mathrm{~min}$. Administration of DM CocE resulted in a significant reversal of the suppressive effects of $3.2 \mathrm{mg} / \mathrm{kg}$ cocaine (dose: $\mathrm{F} 1: \mathrm{F}(5,105)=9.9 ; p<0.001 ; \mathrm{F} 2$ : $\mathrm{F}(3,63)=4.4 ; p<0.01 ; \mathrm{M} 1: \mathrm{F}(5,105)=9.8 ; p<0.001$; time: M1: $\mathrm{F}(21,105)=2.4 ; p<0.01)$, with locomotor activity returning to saline-like levels within the first $5 \mathrm{~min}$ of DM CocE (data not shown). Although similar effects were observed when these data were grouped (dose: $\mathrm{F}(5,220)=6.0 ; p<0.001 ;$ time: $\mathrm{F}(21,220)=1.7 ; p<0.05)$, there was no significant effect of dose when the locomotor activity counts were summed across the entire 120-min session (data not shown).

With respect to core body temperature, DM CocE produced dose-dependent changes in three of the four 
- $3.2 \mathrm{mg} / \mathrm{kg}$ Cocaine + PBS
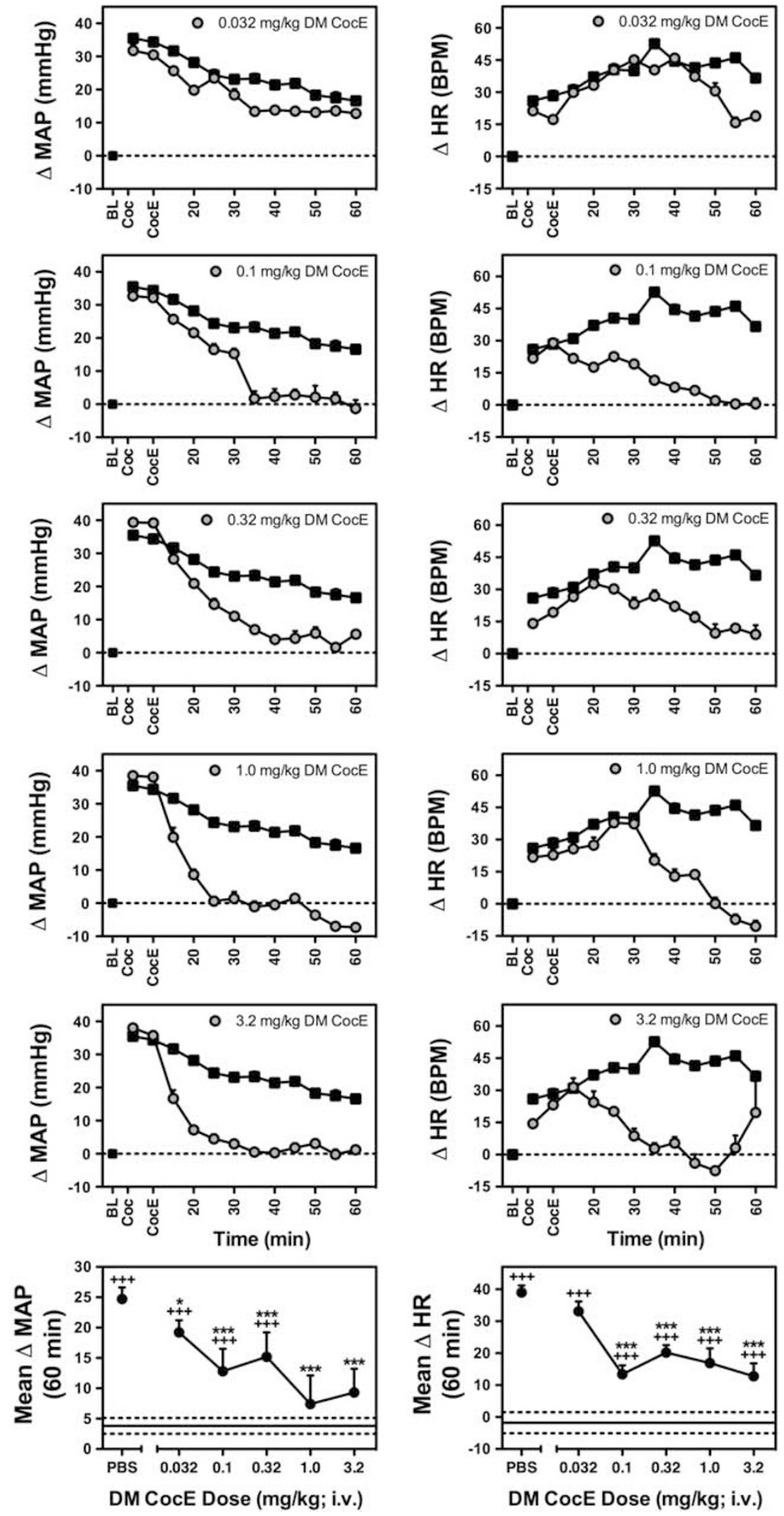

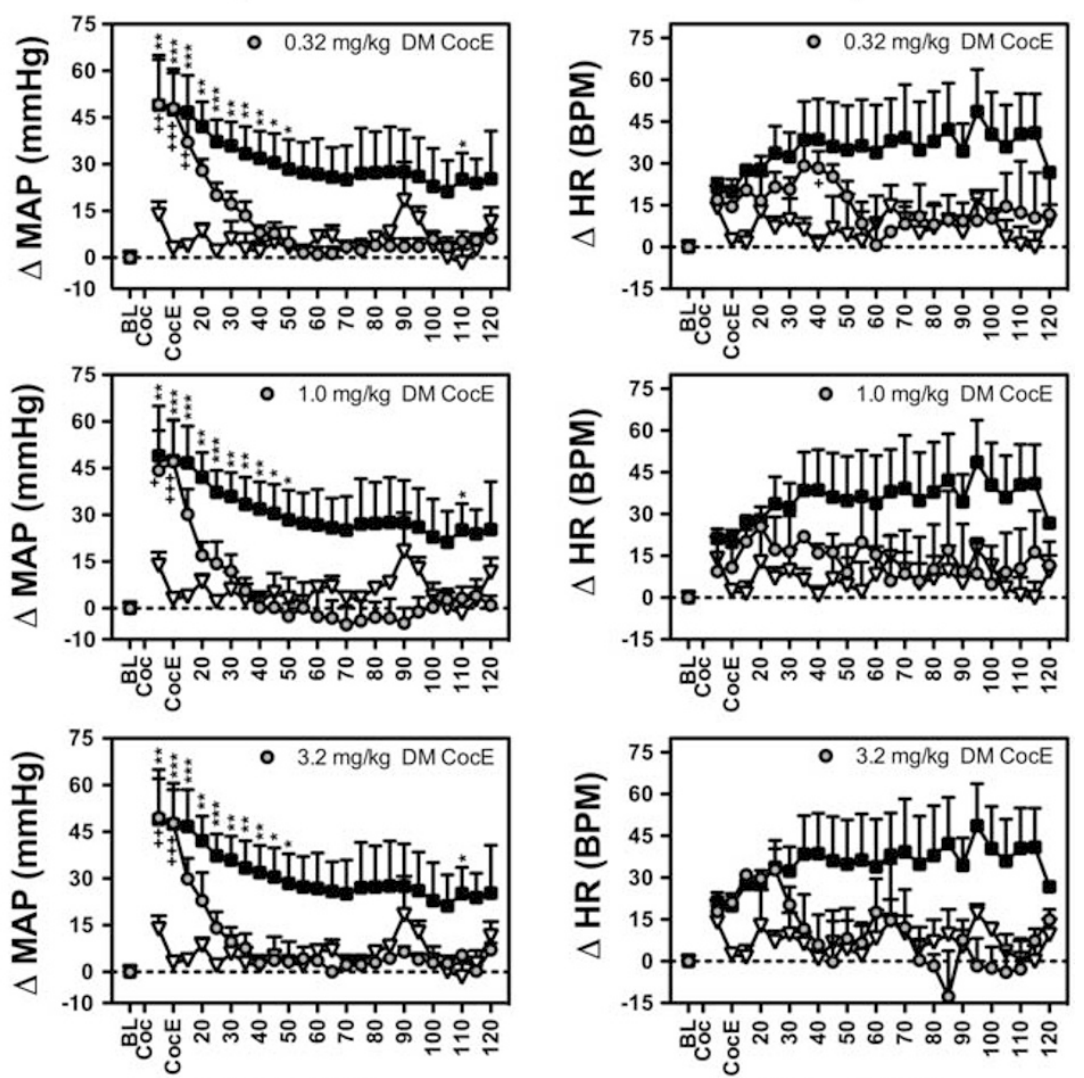

Time (min)
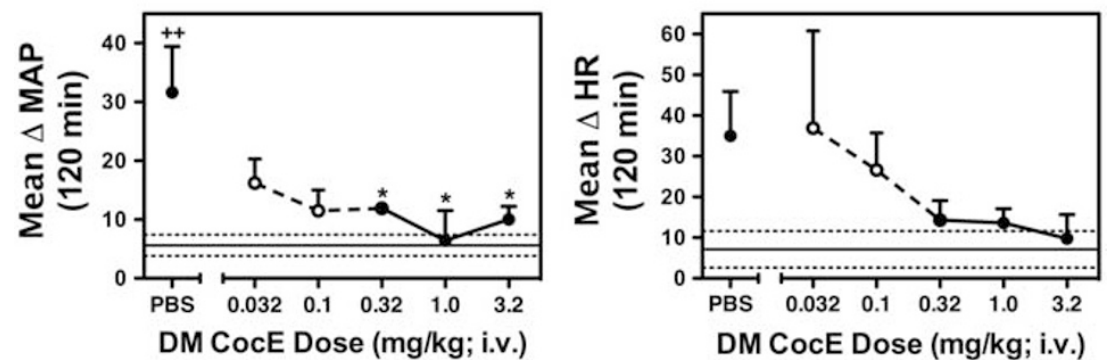

Figure 4 Effects of DM CocE (0.32, I.0, and $3.2 \mathrm{mg} / \mathrm{kg}$; i.v.) on the cocaine-induced changes in mean arterial pressure (MAP; left panels) and heart rate (HR; right panels) when administered $10 \mathrm{~min}$ after a dose of $3.2 \mathrm{mg} / \mathrm{kg}$ i.v. cocaine. Data points represent the mean \pm SEM ( $n=3$ ) change from baseline for MAP or HR over successive 5-min blocks of time, and are compared with the effects observed during sessions in which either saline or $3.2 \mathrm{mg} / \mathrm{kg}$ cocaine were followed by PBS. * $p<0.05$; *** $p<0.01$; **** $p<0.00 \mathrm{I} ;{ }^{+} p<0.05 ;{ }^{++} p<0.0$ I; ${ }^{+++} p<0.00 \mathrm{I}$. Significant difference from saline + PBS condition for the 3.2 cocaine + PBS (*) or 3.2 cocaine + DM CocE $(+)$ conditions as determined by repeated measures, two-way ANOVA with post hoc Bonferroni tests. Dose-response curves for the effects of DM CocE on the mean change in MAP and HR obtained during the I20-min period following cocaine administration. Filled symbols represent conditions in which three monkeys were evaluated, whereas open symbols represent conditions that were excluded from statistical comparisons because of small sample size $(n=2 ; \mathrm{MI}$ and $\mathrm{FI})$. Horizontal lines represent the mean (solid) \pm SEM (dashed) change in MAP or HR obtained during the saline condition for the three monkeys. ${ }^{*} p<0.05 ;{ }^{++} p<0.01$. Significant difference from saline + PBS $(+)$ or the $3.2 \mathrm{mg} / \mathrm{kg}$ cocaine + PBS $(*)$ condition as determined by a one-way ANOVA with post hoc Newman-Keuls tests.

Figure 3 Effects of DM CocE (0.032, 0.1, 0.32, I.0, and $3.2 \mathrm{mg} / \mathrm{kg}$; i.v.) on the cocaine-induced changes in mean arterial pressure (MAP; left panels) and heart rate (HR; right panels) when administered $10 \mathrm{~min}$ after a dose of $3.2 \mathrm{mg} / \mathrm{kg}$ i.v. cocaine in a representative monkey (FI). Data points represent the mean \pm SEM change from baseline for MAP or HR over successive 5-min blocks of time during the first 60 min after cocaine administration, and are compared with the effects observed when PBS followed $3.2 \mathrm{mg} / \mathrm{kg}$ i.v. cocaine. Dose-response curves for the effects of DM CocE on the mean change in MAP and HR obtained during the 60-min period following cocaine administration. Horizontal lines represent the mean (solid) \pm SEM (dashed) change in MAP or HR obtained during the saline + PBS condition. ${ }^{*} p<0.05 ;{ }^{*} * * p<0.001$; ${ }^{+++} p<0.00$ I. Significant difference from saline + PBS ( + ) or the 3.2 mg/kg cocaine + PBS $\left(^{*}\right)$ condition as determined by a one-way ANOVA with post hoc Newman-Keuls tests. 

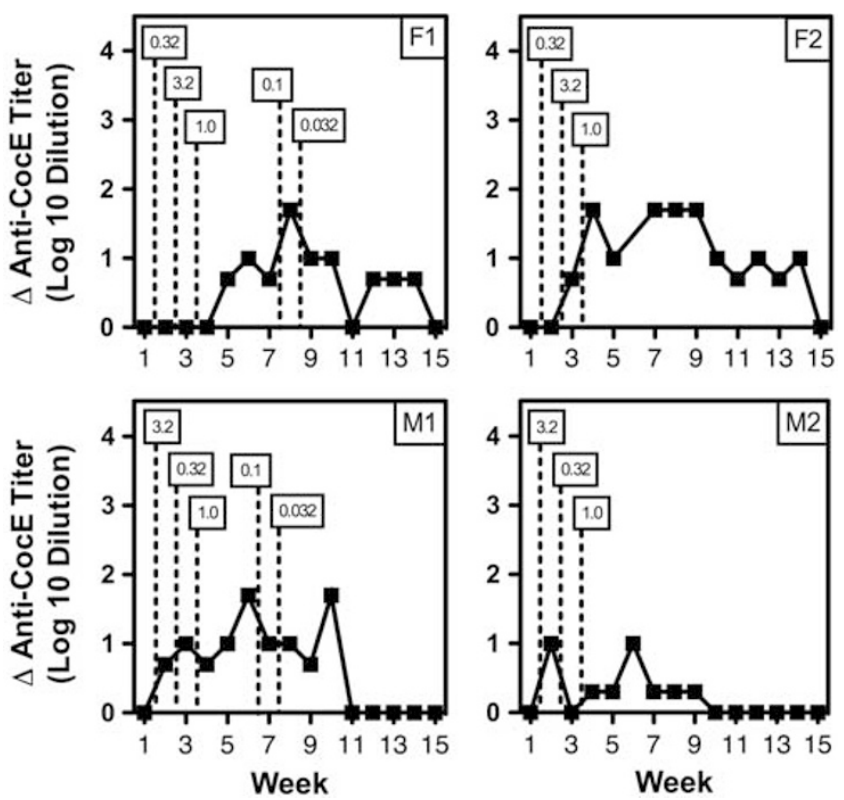

Figure 5 Time course for the development of anti-CocE antibody titers following the repeated administration of DM CocE. Serum samples were collected on a weekly basis, with samples taken $24 \mathrm{~h}$ before test sessions on weeks in which DM CocE was administered. Dashed lines represent the order and timing of the administration of DM CocE doses for individual monkeys.

monkeys, with a reduction of cocaine-induced hyperthermia observed in $\mathrm{M} 1$ and $\mathrm{M} 2(\mathrm{M} 1: \mathrm{F}(5,105)=13.2 ; p<0.001$; M2: $\mathrm{F}(2,42)=101.1 ; p<0.01)$, and a reversal of the hypothermic effects of cocaine observed in F1 $(\mathrm{F}(5,105)=24.7 ; p<0.001)$. There were no significant effects of DM CocE in the fourth monkey (F2). Although there was a significant main effect of DM CocE when the core body temperature data were compared across 5-min bins $(F(5,220)=5.2 ; p<0.001)$, there was no significant effect of DM CocE on the mean change in core body temperature over the entire 120-min session (data not shown).

\section{Immune Responses}

As shown in Figure 5, transient increases in anti-CocE antibody titers were observed in each of the four monkeys. Although $\sim 10$-fold increases in anti-CocE titer levels were observed in monkeys F2, M1, and M2 after the first or second injection, a similar increase in titer was not observed until 2 weeks after the third injection in monkey F1. Similar differences were also observed with regard to the subsequent decreases in anti-CocE antibodies, as baseline levels were observed by weeks 10 and 11 for monkeys M1 and M2, but not until week 15 for monkeys F1 and F2. Moreover, although anti-CocE titers were generally not $>10$-fold in nature, monkey F2 displayed larger increases in anti-CocE titer ( $\sim 100$-fold) that persisted for several weeks following the third dose of DM CocE, whereas similar increases were only occasionally observed in monkeys F1 and M1, but never in monkey M2.

\section{DISCUSSION}

The main findings of the present studies were threefold. First, i.v. cocaine administration produced a reliable, dosedependent increase in MAP and HR in each of the four rhesus monkeys. Second, DM CocE dose dependently and rapidly ameliorated the cardiovascular effects of cocaine when it was administered $10 \mathrm{~min}$ after cocaine. Third, although increases in anti-CocE antibody titers were observed in each of the monkeys, these anti-CocE antibodies did not appear to have a neutralizing effect, as DM CocE effectively reduced the cardiovascular effects of cocaine even when titers were elevated. When taken together, these findings suggest that DM CocE is capable of rapidly reversing the cocaine-induced elevations in MAP and HR, and strongly support the notion that highly efficient cocaine-hydrolyzing enzymes, such as DM CocE, may provide a valuable therapeutic option for the treatment of acute cocaine toxicity in humans.

Although patients with acute cocaine toxicity can present with a variety of symptoms, the most commonly reported reason for ED admission is cocaine-associated chest pain resulting from the cardiovascular effects of cocaine that typically occur within the first hour after use. In humans, the cardiovascular effects of cocaine are closely linked to circulating cocaine levels insofar as increases in MAP and HR appear shortly after use, and dissipate as cocaine is metabolized (see, eg, Evans et al, 1996; Foltin and Fischman, 1991; Javaid et al, 1978). Similar increases in MAP and HR have been observed with cocaine in a variety of species, including rats (see, eg, Tella et al, 1991b, 1992), dogs (see, eg, Wilkerson, 1988), and squirrel monkeys (see, eg, Tella et al, 1990, 1991a,b). However, unlike what is observed in humans, the cardiovascular effects of cocaine in dogs and rats are much shorter lived than the plasma cocaine levels. Curiously, despite their widespread use in drug abuse research, relatively little is known about the cardiovascular effects of cocaine in rhesus monkeys. Matsuzaki et al (1976, 1978) have reported peak increases in HR of $\sim 50-80 \%$ following an i.v. dose of $4.0 \mathrm{mg} / \mathrm{kg}$ cocaine in chaired monkeys, and similar increases in HR combined with modest increases in blood pressure $(\sim 10-20 \%)$ have also been reported in one rhesus monkey trained to smoke cocaine $(0.5-3.0 \mathrm{mg} / \mathrm{kg})$ in a multiple trials procedure (Carroll et al, 1990).

The current studies are the first to provide a detailed description of the cardiovascular effects of cocaine in rhesus monkeys, with reliable, dose-dependent increases in MAP and HR observed following i.v. doses of $0.32-3.2 \mathrm{mg} / \mathrm{kg}$ cocaine. Unlike the transient increases in MAP and HR that have been described in rats and dogs (Tella et al, 1991b; Wilkerson, 1988), the cardiovascular effects of cocaine in rhesus monkeys were long lived, with significant increases in MAP observed for 15, 45, and $115 \mathrm{~min}$ following administration of doses of $0.32,1.0$, and $3.2 \mathrm{mg} / \mathrm{kg}$ cocaine, respectively. Although there was slightly more variability with regard to the HR stimulating effects of cocaine, persistent increases in HR were observed throughout the 120 -min observation period following an i.v. dose of $3.2 \mathrm{mg} /$ $\mathrm{kg}$ cocaine. Importantly, these cardiovascular changes were not only of a duration similar to those observed in squirrel monkeys and humans (see, eg, Javaid et al, 1978; Tella et al, 
1990), but the peak increases in MAP and HR produced by the $1.0 \mathrm{mg} / \mathrm{kg}$ dose of cocaine were also similar to those reported in humans with doses $(32 \mathrm{mg}$ i.v. or $50 \mathrm{mg}$ smoked) that produce equivalent plasma cocaine levels of $\sim 300 \mathrm{ng} / \mathrm{ml}$ (see, eg, Evans et al, 1996; Evans and Foltin, 2004; Foltin and Fischman, 1991; Haney et al, 2010; Javaid et al, 1978; Mello et al, 2002). This suggests that rhesus monkeys and humans have similar sensitivities to the cardiovascular effects of cocaine.

Although a clear correspondence between cocaine blood levels and acute cocaine toxicity has been difficult to establish, a study of 112 cocaine-related ED patients reported an average cocaine blood level of $260 \pm 500 \mathrm{ng} / \mathrm{ml}$ at $\sim 2 \mathrm{~h}$ after admission (Blaho et al, 2000), suggesting that blood levels may have approached $1000 \mathrm{ng} / \mathrm{ml}$ at the time of admission. Similarly, high cocaine levels are commonly reported in post mortem overdose fatality studies (Finkle and McCloskey, 1978; Karch et al, 1998; Koehler et al, 2005). Thus, therapeutics aimed at alleviating acute cocaine toxicity in humans by pharmacokinetic mechanisms (metabolism or sequestration of cocaine) should be able to rapidly reduce the physiological and/or behavioral effects associated with cocaine concentrations of $\sim 1000 \mathrm{ng} / \mathrm{ml}$. Although the current study focused on reversing the cardiovascular effects of cocaine, and not the clearance of cocaine from the blood, the similarities between the pharmacokinetic properties of cocaine in rhesus monkeys and humans (see, eg, Foltin and Fischman, 1991; Javaid et al, 1978; Mello et al, 2002; Mendelson et al, 1999) suggest that an i.v. dose of $3.2 \mathrm{mg} / \mathrm{kg}$ cocaine in the rhesus monkey should produce blood levels of cocaine that approximate those that might be expected at the time of ED admission.

Similar to the effects of cocaine during the initial doseresponse determination, MAP and HR were elevated throughout the 120-min session when administration of $3.2 \mathrm{mg} / \mathrm{kg}$ i.v. cocaine was followed by administration of PBS. Administration of DM CocE resulted in a dose- and time-dependent amelioration of the hypertensive and tachycardic effects of cocaine, with saline-like measures of MAP and HR observed within the first 5-10 min and 20-40 min after administration of doses of $0.32-3.2 \mathrm{mg} / \mathrm{kg}$ DM CocE, respectively. Moreover, the hypertensive effects of cocaine were completely eliminated within the first 20-30 min following DM CocE administration, after which MAP remained at baseline-like levels for the remainder of the session. That the reversal of the cocaine-induced increases in HR were delayed was not surprising given that the tachycardic effects of cocaine in squirrel monkeys appeared to have a prolonged duration when compared with cocaine-induced increases in MAP (see, eg, Tella et al, 1990), suggesting that the hypertensive effects may be more closely tied to circulating levels of cocaine. DM CocE was equally effective at reversing the increases in MAP and HR produced by $1.0 \mathrm{mg} / \mathrm{kg}$ cocaine. Interestingly, unlike the development of tolerance to the convulsant effects of cocaine described by Matsuzaki et al (1976), monkey M2 became increasingly sensitive to the convulsant effects of cocaine over the course of the study, and had to be removed before a full range of doses could be evaluated.

Although Matsuzaki et al (1976) also described a rapid development of tolerance to the tachycardic effects of daily doses of $4.0 \mathrm{mg} / \mathrm{kg}$ i.v. cocaine in rhesus monkeys, the mean change in MAP and HR observed during the first $10 \mathrm{~min}$ (in the absence of DM CocE) of repeated testing with cocaine and DM CocE was no different from that what was observed during the initial dose-response determinations, suggesting that separating dosing conditions by at least 7 days was sufficient to reduce the development of tolerance for the group as a whole. However, it should be noted that one of the monkeys (F2) appeared to develop a slight tolerance to the cardiovascular effects of $3.2 \mathrm{mg} / \mathrm{kg}$ cocaine following the initial exposure, with a decreased HR response, and a slightly shorter MAP response to $3.2 \mathrm{mg} / \mathrm{kg}$ cocaine during the DM CocE dosing conditions. Curiously, this monkey also displayed the greatest peak increase in MAP following administration of $3.2 \mathrm{mg} / \mathrm{kg}$ cocaine, suggesting that the reduced HR response may have been because of the baroreceptor reflex that provides a negative feedback mechanism to reduce MAP by decreasing HR, rather than tolerance to the cardiovascular effects of cocaine. Nevertheless, that cocaine produced reliable increases in MAP before DM CocE administration throughout the study indicates that the rapid decreases in MAP and HR observed after DM CocE administration can be attributed to the metabolism of cocaine by DM CocE.

The finding that DM CocE is capable of ameliorating the cardiovascular effects of large doses of cocaine in rhesus monkeys is in agreement with a previous study of wt CocE in rats, and provides further support for the use of cocainehydrolyzing enzymes to treat acute cocaine toxicity. In rats, wt CocE was shown to prevent and reverse not only the increases in MAP and decreases in HR, but also the ECG changes and increases in cardiac troponin I when administered $1 \mathrm{~min}$ before or after a LD100 dose of cocaine $(180.0 \mathrm{mg} / \mathrm{kg}$; intraperitoneal (i.p.)), as well as $1 \mathrm{~min}$ after the onset of convulsion (Wood et al, 2010). Importantly, these authors also showed that although the benzodiazepine midazolam was capable of significantly reducing the occurrence of convulsion, midazolam did not affect the cardiovascular changes, accumulation of cardiac troponin I, or lethality when administered $1 \mathrm{~min}$ after a LD100 dose of cocaine. Interestingly, although cocaine-specific antibodies and cocaine-hydrolyzing enzymes, such as DM CocE, are both capable of reducing the self-administration of cocaine in laboratory animals (Carrera et al, 2000; Collins et al, 2009; Fox et al, 1996), CocE appears to have distinct advantages with respect to cocaine toxicity. For instance, despite a significant reduction in the subjective ratings of 'good drug effect', and 'cocaine quality', Haney et al (2010) recently reported significant increases in the peak HR response to smoked cocaine in human patients with high anti-cocaine antibody titers, an effect that is likely because of the increased plasma cocaine levels resulting from the antibody sequestration of cocaine within the periphery. Thus, in addition to providing distinct advantages over benzodiazepines for the treatment of the cardiovascular complications of cocaine, cocaine-hydrolyzing enzymes, such as DM CocE, would also appear to provide an added margin of safety should a suitable, longer acting candidate be developed as a pharmacotherapy for cocaine abuse.

However, CocE is a bacterial protein, and previous studies with the wt form of CocE have reported $\sim 10-100$-fold increases in anti-CocE antibody titers following repeated exposure in mice (Ko et al, 2007, 2009). Although these 
increases in anti-CocE antibodies did result in a reduction of the protective effects of wt CocE against a LD100 dose of cocaine in mice, it is important to note that these neutralizing effects were overcome by increasing doses of wt CocE. Although the current studies were not designed to investigate systematically the immunogenic effects of DM CocE, a similar $\sim 10-100$-fold increase in anti-CocE titers was observed following the repeated administration of DM CocE in rhesus monkeys. These increases in anti-CocE titer, however, did not appear to alter significantly the capacity of DM CocE to reduce the cardiovascular effects of cocaine, although it is unclear if the lower doses $(0.032$ and $0.1 \mathrm{mg} /$ $\mathrm{kg}$ ) of DM CocE would have been more effective in monkeys F1 and M1 had they been tested before the development of anti-CocE antibodies. Further studies are needed to more fully evaluate the interactions between the immunogenic effects of DM CocE and the capacity of DM CocE to eliminate the effects of cocaine in rhesus monkeys.

In summary, these studies are the first to provide a detailed dose-response analysis of the cardiovascular effects of cocaine in the rhesus monkey, and importantly, they are the first to document the effectiveness of a longer-acting CocE mutant in ameliorating the cardiovascular effects of cocaine in primates. Following i.v. administration, cocaine produced dose-dependent increases in MAP and HR that were of a magnitude and duration similar to that what is observed in humans, with significant increases in MAP observed for up to $115 \mathrm{~min}$ after an i.v. dose of $3.2 \mathrm{mg} / \mathrm{kg}$ cocaine. Treatment with DM CocE 10 min after cocaine administration resulted in a dose-dependent and rapid amelioration of the cocaine-induced increases in MAP and HR in rhesus monkeys, with MAP returning to baseline levels within 5-10 min after the administration of DM CocE at doses as low as $0.32 \mathrm{mg} / \mathrm{kg}$. A similar dose-dependent reversal of cocaine-induced increases in HR was also observed, and once reduced, MAP and HR measures remained at baseline-like levels for the duration of the observation period. In conclusion, the results of these studies provide strong support for the notion that therapeutics that accelerate the metabolism of cocaine would effectively reduce the cardiovascular and behavioral effects of cocaine, and that DM CocE could provide a powerful therapeutic option for treatment of acute cocaine intoxication.

\section{ACKNOWLEDGEMENTS}

We acknowledge Dr Gail Winger for her editorial assistance, and Yong-Gong Shi for his surgical expertise. This research was supported by the USPHS Grants DA 021416 and DA 023213 from NIDA.

\section{DISCLOSURE}

GTC, KAC, JN, AAB, and NWL declare that, except for income received from their primary employer, no financial support or compensation has been received from any individual or corporate entity over the past 3 years for research or professional service, and none of the authors have personal financial holdings that could be perceived as constituting a potential conflict of interest. RKS, MCK, DN, and JHW are listed as inventors on the patent for DM CocE. RKS and JHW have received consulting funds from Reckitt Benckiser Pharmaceuticals concerning cocaine esterase. JHW was also supported by Sunovion and Alkermes. The University of Michigan, Columbia University, and the University of Kentucky have licensed the potential development and use of cocaine esterase and mutants to Reckitt Benckiser Pharmaceuticals for acute cocaine toxicity. M-C Ko was supported by SSV Therapeutics, BioXell S.p.A., and Purdue Pharma L.P., and Sunovion. The other authors declare no conflict of interest.

\section{REFERENCES}

Baird TJ, Deng SX, Landry DW, Winger G, Woods JH (2000). Natural and artificial enzymes against cocaine. I. Monoclonal antibody $15 \mathrm{~A} 10$ and the reinforcing effects of cocaine in rats. J Pharmacol Exp Ther 295: 1127-1134.

Baumann BM, Perrone J, Hornig SE, Shofer FS, Hollander JE (2000). Randomized, double-blind, placebo-controlled trial of diazepam, nitroglycerin, or both for treatment of patients with potential cocaine-associated acute coronary syndromes. Acad Emerg Med 7: 878-885.

Blaho K, Logan B, Winbery S, Park L, Schwilke E (2000). Blood cocaine and metabolite concentrations, clinical findings, and outcome of patients presenting to an ED. Am J Emerg Med 18: 593-598.

Brimijoin S, Gao Y, Anker JJ, Gliddon LA, Lafleur D, Shah R et al (2008). A cocaine hydrolase engineered from human butyrylcholinesterase selectively blocks cocaine toxicity and reinstatement of drug seeking in rats. Neuropsychopharmacology 33: 2715-2725.

Brody SL, Slovis CM, Wrenn KD (1990). Cocaine-related medical problems: consecutive series of 233 patients. Am J Med 88: 325-331.

Carrera MR, Ashley JA, Zhou B, Wirsching P, Koob GF, Janda KD (2000). Cocaine vaccines: antibody protection against relapse in a rat model. Proc Natl Acad Sci USA 97: 6202-6206.

Carroll ME, Krattiger KL, Gieske D, Sadoff DA (1990). Cocainebase smoking in rhesus monkeys: reinforcing and physiological effects. Psychopharmacology (Berl) 102: 443-450.

Collins GT, Brim RL, Narasimhan D, Ko MC, Sunahara RK, Zhan CG et al (2009). Cocaine esterase prevents cocaine-induced toxicity and the ongoing intravenous self-administration of cocaine in rats. J Pharmacol Exp Ther 331: 445-455.

Cooper ZD, Narasimhan D, Sunahara RK, Mierzejewski P, Jutkiewicz EM, Larsen NA et al (2006). Rapid and robust protection against cocaine-induced lethality in rats by the bacterial cocaine esterase. Mol Pharmacol 70: 1885-1891.

Evans SM, Cone EJ, Henningfield JE (1996). Arterial and venous cocaine plasma concentrations in humans: relationship to route of administration, cardiovascular effects and subjective effects. J Pharmacol Exp Ther 279: 1345-1356.

Evans SM, Foltin RW (2004). Pharmacokinetics of intravenous cocaine across the menstrual cycle in rhesus monkeys. Neuropsychopharmacology 29: 1889-1900.

Fareed FN, Chan G, Hoffman RS (2007). Death temporally related to the use of a Beta adrenergic receptor antagonist in cocaine associated myocardial infarction. J Med Toxicol 3: 169-172.

Finkle BS, McCloskey KL (1978). The forensic toxicology of cocaine (1971-1976). J Forensic Sci 23: 173-189.

Foltin RW, Fischman MW (1991). Smoked and intravenous cocaine in humans: acute tolerance, cardiovascular and subjective effects. J Pharmacol Exp Ther 257: 247-261.

Fox BS, Kantak KM, Edwards MA, Black KM, Bollinger BK, Botka AJ et al (1996). Efficacy of a therapeutic cocaine vaccine in rodent models. Nat Med 2: 1129-1132. 
Gao D, Narashihan DL, Macdonald J, Brim R, Ko MC, Landry DW et al (2008). Thermostable variants of cocaine esterase for long-time protection against cocaine toxicity. Mol Pharmacol 75: 318-323.

Glauser J, Queen JR (2007). An overview of non-cardiac cocaine toxicity. J Emerg Med 32: 181-186.

Haney M, Gunderson EW, Jiang H, Collins ED, Foltin RW (2010). Cocaine-specific antibodies blunt the subjective effects of smoked cocaine in humans. Biol Psychiatry 67: 59-65.

Hollander JE (1995). The management of cocaine-associated myocardial ischemia. $N$ Engl J Med 333: 1267-1272.

Hollander JE, Henry TD (2006). Evaluation and management of the patient who has cocaine-associated chest pain. Cardiol Clin 24: $103-114$.

Javaid JI, Fischman MW, Schuster CR, Dekirmenjian H, Davis JM (1978). Cocaine plasma concentration: relation to physiological and subjective effects in humans. Science 202: 227-228.

Jeffcoat AR, Perez-Reyes M, Hill JM, Sadler BM, Cook CE (1989). Cocaine disposition in humans after intravenous injection, nasal insufflation (snorting), or smoking. Drug Metab Dispos 17: 153-159.

Jutkiewicz EM, Baladi MG, Cooper ZD, Narasimhan D, Sunahara RK, Woods JH (2008). A bacterial cocaine esterase protects against cocaine-induced epileptogenic activity and lethality. Ann Emerg Med 54: 409-420.

Karch SB, Stephens B, Ho CH (1998). Relating cocaine blood concentrations to toxicity-an autopsy study of 99 cases. J Forensic Sci 43: 41-45.

Ko MC, Bowen LD, Narasimhan D, Berlin AA, Lukacs NW, Sunahara RK et al (2007). Cocaine esterase: interactions with cocaine and immune responses in mice. J Pharmacol Exp Ther 320: 926-933.

Ko MC, Narasimhan D, Berlin AA, Lukacs NW, Sunahara RK, Woods JH (2009). Effects of cocaine esterase following its repeated administration with cocaine in mice. Drug Alcohol Depend 101: 202-209.

Koehler SA, Ladham S, Rozin L, Shakir A, Omalu B, Dominick J et al (2005). The risk of body packing: a case of a fatal cocaine overdose. Forensic Sci Int 151: 81-84.

Larsen NA, Turner JM, Stevens J, Rosser SJ, Basran A, Lerner RA et al (2002). Crystal structure of a bacterial cocaine esterase. Nat Struct Biol 9: 17-21.

Matsuzaki M, Spingler PJ, Misra AL, Mule SJ (1976). Cocaine: tolerance to its convulsant and cardiorespiratory stimulating effects in the monkey. Life Sci 19: 193-203.

Matsuzaki M, Spingler PJ, Whitlock EG, Misra AL, Mule SJ (1978). Comparative effects of cocaine and pseudococaine on EEG activities, cardiorespiratory functions, and self-administration behavior in the rhesus monkey. Psychopharmacology (Berl) 57: 13-20.

McCord J, Jneid H, Hollander JE, de Lemos JA, Cercek B, Hsue P et al (2008). Management of cocaine-associated chest pain and myocardial infarction: a scientific statement from the American Heart Association Acute Cardiac Care Committee of the Council on Clinical Cardiology. Circulation 117: 1897-1907.

Mello NK, Bowen CA, Mendelson JH (2002). Comparison of plasma cocaine levels during a 'binge' pattern of cocaine administration in male and female rhesus monkeys. Psychopharmacology (Berl) 164: 19-26.
Mendelson JH, Mello NK, Sholar MB, Siegel AJ, Kaufman MJ, Levin JM et al (1999). Cocaine pharmacokinetics in men and in women during the follicular and luteal phases of the menstrual cycle. Neuropsychopharmacology 21: 294-303.

Mets B, Winger G, Cabrera C, Seo S, Jamdar S, Yang G et al (1998). A catalytic antibody against cocaine prevents cocaine's reinforcing and toxic effects in rats. Proc Natl Acad Sci USA 95: 10176-10181.

Mittleman MA, Mintzer D, Maclure M, Tofler GH, Sherwood JB, Muller JE (1999). Triggering of myocardial infarction by cocaine. Circulation 99: 2737-2741.

Narasimhan D, Nance MR, Gao D, Ko MC, Macdonald J, Tamburi $\mathrm{P}$ et al (2010). Structural analysis of thermostabilizing mutations of cocaine esterase. Protein Eng Des Sel 23: 537-547.

Pan Y, Gao D, Yang W, Cho H, Yang G, Tai HH et al (2005). Computational redesign of human butyrylcholinesterase for anticocaine medication. Proc Natl Acad Sci USA 102: 16656-16661.

Perez-Reyes M, Jeffcoat AR, Myers M, Sihler K, Cook CE (1994). Comparison in humans of the potency and pharmacokinetics of intravenously injected cocaethylene and cocaine. Psychopharmacology (Berl) 116: 428-432.

SAMHSA (2008). Results from the 2007 National Survey on Drug Use and Health: National Findings. Office of Applied Studies, NSDUH Series H-34, DHHS Publication No SMA 08-4343 Office of Applied Studies: Rockville, MD.

SAMHSA (2010). Drug Abuse Warning Network, 2007: National Estimates of Drug-Related Emergency Department Visits. Office of Applied Studies: Rockville, MD.

Tella SR, Schindler CW, Goldberg SR (1990). The role of central and autonomic neural mechanisms in the cardiovascular effects of cocaine in conscious squirrel monkeys. J Pharmacol Exp Ther 252: 491-499.

Tella SR, Schindler CW, Goldberg SR (1991a). Cardiovascular effects of cocaine in squirrel monkeys. NIDA Res Monogr 108: 74-91.

Tella SR, Schindler CW, Goldberg SR (1991b). Rapid sensitization to the cardiovascular effects of cocaine in rats. Eur J Pharmacol 194: 119-122.

Tella SR, Schindler CW, Goldberg SR (1992). Cardiovascular effects of cocaine in conscious rats: relative significance of central sympathetic stimulation and peripheral neuronal monoamine uptake and release mechanisms. J Pharmacol Exp Ther 262: 602-610.

Turner JM, Larsen NA, Basran A, Barbas III CF, Bruce NC, Wilson IA et al (2002). Biochemical characterization and structural analysis of a highly proficient cocaine esterase. Biochemistry 41: 12297-12307.

Wilkerson RD (1988). Cardiovascular effects of cocaine in conscious dogs: importance of fully functional autonomic and central nervous systems. J Pharmacol Exp Ther 246: 466-471.

Willette AA, Lubach GR, Coe CL (2007). Environmental context differentially affects behavioral, leukocyte, cortisol, and interleukin-6 responses to low doses of endotoxin in the rhesus monkey. Brain Behav Immun 21: 807-815.

Wood SK, Narasimhan D, Cooper Z, Sunahara RK, Woods JH (2010). Prevention and reversal by cocaine esterase of cocaineinduced cardiovascular effects in rats. Drug Alcohol Depend 106: 219-229. 